\title{
A confluence of unanimity
}

\author{
Stephen Hancocks OBE \\ Editor-in-Chief
}

The BDJ Upfront section includes editorials, letters, news, book reviews and interviews. Please direct your correspondence to the News Editor,

Kate Quinlan at k.quinlan@nature.com. Press releases or articles may be edited, and should include a colour photograph if possible.

$\mathrm{T}$ he papers for each issue of the Journal are brought together at a production meeting held three to four weeks

before the publication date, depending on time of the year, holidays and various other considerations. The main papers are allocated to the issue according to the dates on which they have been accepted. These dates, in turn, are dependent on a variety of factors; when the paper was originally submitted, how long the referees took to reply, the length of time that the authors took to make any modifications and so forth. Consequently, the selection is not exactly random but is sufficiently subject to chance so as to make the juxtaposition of content at least arbitrary.

Given this process it fascinates me that from time to time the contents of a particular issue despite coming from a rich mix of authors, backgrounds and inspirations coalesce to create a set of supportive and constructive pieces which when taken as a whole provide an unintended but coherent narrative. Consequently, here we have papers on substance abuse and conscious sedation, body dysmorphic disorder and facial aesthetics, and timing and skills mix in primary dental care. ${ }^{1,2,3}$ When so listed there is little apparent connection between them and yet what emerges is a story of how good patient care requires time to achieve. At the centre of the experience conveyed in these separate works is the unifying description of how we are providing oral care, not just dentistry, for individuals not just a homogenous bunch plucked from the general public.

Even if we do not provide facial aesthetics the associated dilemmas will probably be familiar to us in relation to patients whose expectations of how they will look after treatment are too extreme. Some believe that improving their appearance will change other aspects of their lives radically for the better; employment prospects, social engagement, romance, when in reality the cause or causes of their discomfort lay elsewhere. Elucidating whether or not they may have some degree of body dysmorphic disorder might seem on one hand a slightly irrelevant angle of academic curiosity. Yet on a very practical level, quite apart from helping diagnose a recognised condition, it may save the practitioner from subsequent litigation since cases brought by those disillusioned by the apparently poor aesthetic outcome can easily claim to have been misled or misinformed. But this process takes time. The authors acknowledge this in having worked on a short form of the fuller questionnaire for diagnosis but the fact remains that this requires additional time to be spent discovering the situation and defining the needs of the individual. One suspects that this is likely to off-the-shelf remedies points towards a future delivery service of oral care that will have to accommodate personalities and personal imperatives, and not just teeth and gums.

The skill mix paper also reports that 'perceived influences on the length of time required to complete dental procedures were patient complexity, system of care, type of remuneration system and philosophy of care emphasising quality, together with practice environment...'3

This speaks not only to the generality of care but to the specifics of diverse patients described in the other papers. ${ }^{1,2}$ One is left in little doubt that the current UDA system of remuneration in England, for example, fails utterly to address such important shifts in emphasis. While it

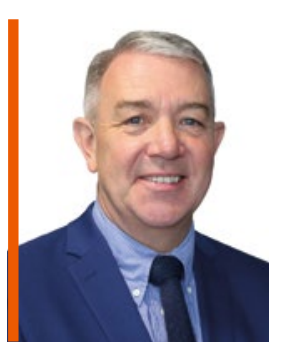

\section{'We are providing oral care, not just dentistry, for individuals not just a homogenous bunch plucked from the general public...'}

take longer than placing a class I restoration, for example, and so pitches our long-standing evaluative measures of quantity in direct conflict with an arguably more patient-centred approach to the consideration of quality.

This is where the juxtaposition of papers becomes so interesting, as in the paper on skill mix and timings a dentist is recorded in a focus group (itself a form of qualitative rather than quantitative research) reporting that, ' $A$ well-behaved patient with a clean mouth and who goes numb quickly and who sits still through the procedure is a boon!' In terms of pure productivity few of us could disagree with this sentiment but such a creature is a member of a retreating species. The rapidly dwindling stock of patients presenting with twentieth century caries patterns requiring previously pragmatic is difficult to foresee a model other than that offered by a private route which would provide an obvious solution it cannot be outwith the wit of clever people to devise systems to allow quality over quantity whilst also enabling livings to be made. But that will clearly require the adjacent publication of another paper altogether - any offers?

\section{References}

1. Hasan A, Sharma V. Substance abuse and conscious sedation: theoretical and practical considerations. $\mathrm{Br}$ Dent J 2019; 227: 923-927.

2. James M, Clarke P, Darcey R. Body dysmorphic disorder and facial aesthetic treatments in dental practice. $\mathrm{Br}$ Dent J 2019; 227: 929-933.

3. Ganbavale S G, Aukett J W, Gallagher J E. Timings and skill mix in primary dental care: a pilot study. Br Dent J 2019; 227: 907-913.

https://doi.org/10.1038/s41415-019-1005-0 